\title{
$\beta$-chloroaldehydes from trapping zirconium enolates produced in asymmetric 1,4-additions
}

\author{
Jiao Yu (Joseph) Wang, Thomas Palacin, Stephen P. Fletcher* \\ Chemistry Research Laboratory, University of Oxford, 12 Mansfield Road, Oxford OX1 3TA, UK \\ Supporting Information Placeholder
}

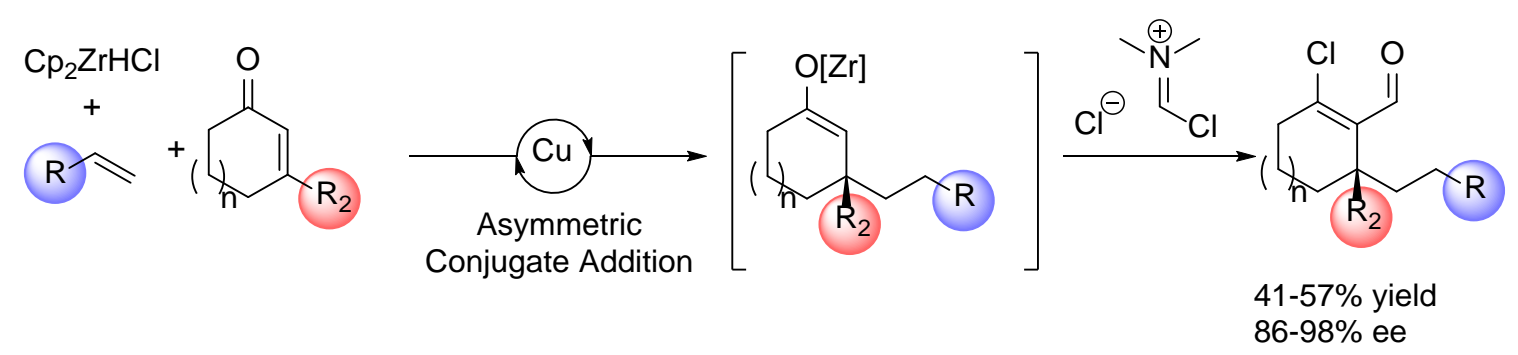

\begin{abstract}
Zirconium enolates, derived from copper catalyzed asymmetric conjugate additions, are trapped with the VilsmeierHaack reagent. Asymmetric additions generate quaternary carbon centers with high enantioselectivity (generally $~ 90 \%$ ee) and the enolates are converted to unsaturated $\beta$-chloroaldehydes (41-57\% yields). The reaction tolerates changes to the nucleophile, can be used to form five, six or seven membered ring products, is scalable to $5 \mathrm{mmol}$ and the products are readily elaborated by condensation, cross coupling and addition reactions.
\end{abstract}

Asymmetric conjugate addition (ACA) is a staple of the organic chemist's toolkit for C-C bond formation. When performed in sequence with an electrophilic trapping reaction, the resulting tandem sequences are particularly powerful ${ }^{1 \mathrm{a}-\mathrm{d}}$ (Scheme 1, A). As multiple bonds and stereocenters may be formed in one step, this strategy is frequently used in natural product synthesis. $^{\text {2a-g }}$.

Many ACA/trapping reactions are initiated by organometallic nucleophiles such as Grignard, organoaluminum and organozinc reagents. The intermediate enolates generated from these ACAs have been trapped in a variety of ways ${ }^{1}$, including with Mander's reagent, ${ }^{3}$ the Heller-Sarpong reagent, ${ }^{4}$ carbenium ions, ${ }^{5}$ nitro-olefins ${ }^{6}$ and Stork-Jung electrophiles. ${ }^{7}$ Trapping intermediate aluminium enolates has been extensively investigated by Alexakis and co-workers. ${ }^{8,9}$ Generally, tandem ACA/trapping reactions remain strongly substrate dependent $^{3,8,10-12}$ and developing new trapping methods would facilitate chemists ability to rapidly access complex molecules.

Our group has developed ACAs that use alkylzirconium species as nucleophiles. These organometallics are made in situ from hydrozirconation of alkenes with $\mathrm{Cp}_{2} \mathrm{ZrHCl}$, tolerate a variety of functional groups, and can be generated and used at convenient temperatures. We have shown that these alkylzirconium reagents add to a variety of cyclic and acyclic enones to furnish ACA products bearing tertiary or quaternary stereocenters in high yield and enantioselectivity. ${ }^{13}$
Scheme 1. A) General scheme of the tandem ACA/trapping reaction B) Previous work ${ }^{15}$ and this work.

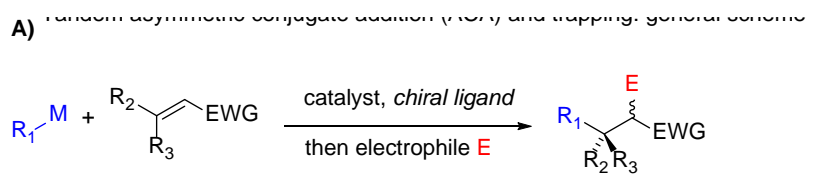

B) Trapping of zirconium enolates using hydrozirconated alkenes as nucleophiles

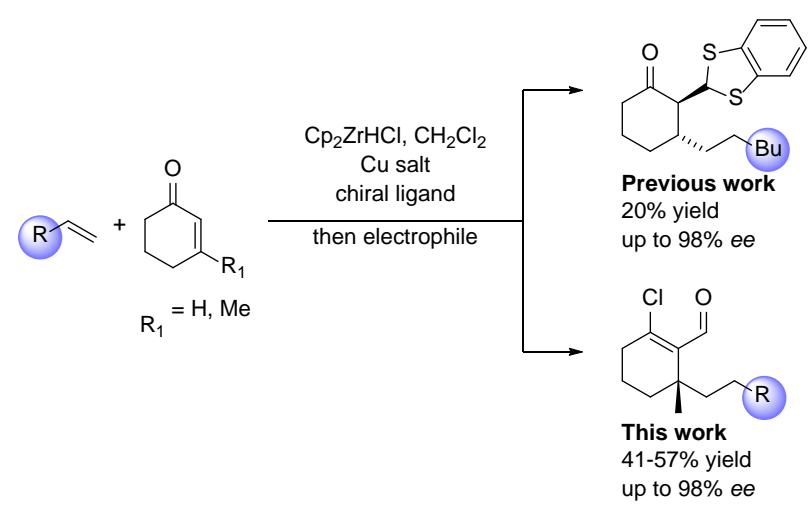

The development of tandem ACA/trapping reactions initiated by organozirconium reagents have been difficult to realize, possibly because of the strength of the $\mathrm{Zr}-\mathrm{O}$ bond in the intermediate enolate $^{14}$, however Nemethova et al. recently demonstrated that a few specialized electrophiles can be used to trap zirconium enolates 
(Scheme 1, B). ${ }^{15}$ In that work, highly electrophilic carbenium ions gave trapped products in $<20 \%$ yield.

Here, we report a synthetically useful tandem ACA/trapping procedure initiated by copper catalyzed ACA of alkylzirconium species to form quaternary centers ${ }^{13}$ followed by trapping of the intermediate enolate with the Vilsmeier-Haack reagent (VH) (Table 1, 2). ${ }^{16}$ Unsaturated $\beta$-chloroaldehydes are the products of this sequence (Scheme $1, \mathbf{B}$ ) which (vida infra) can readily be elaborated in a number of ways. $\mathrm{VH}$ is well known as a strong formylating agent, and under certain conditions behaves as both a formylating and chlorinating agent. ${ }^{17}$

The use of highly reactive electrophiles was initially investigated to trap enolates generated in ACAs as shown in Table $1^{13 d, e}$ Although $\alpha$-hydroxy ketone product $8\left(\mathrm{R}=\mathrm{CH}_{2} \mathrm{OH}\right)$ could be obtained using formaldehyde $\mathbf{1}$, and $\mathbf{8}$ was potentially amenable to further functionalization, the yields were difficult to reliably reproduce, and there is procedural complexity in generating gaseous anhydrous formaldehyde (Table 1, entry 1).

Table 1. ${ }^{a}$ Investigation of electrophiles used in zirconium enolate trapping.
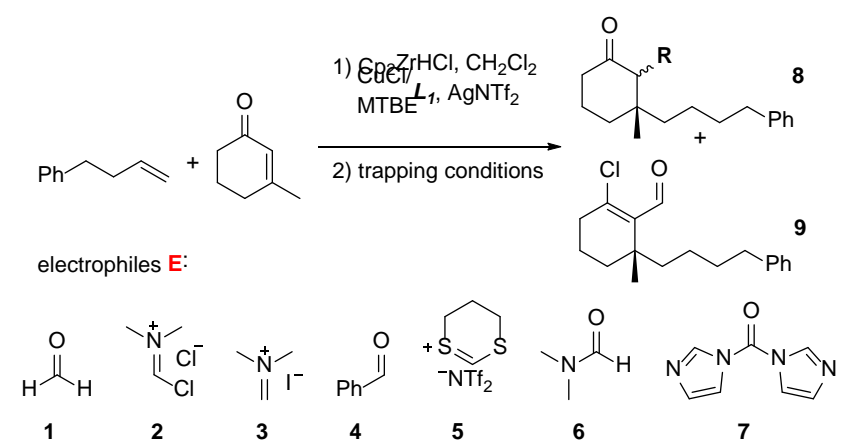

\begin{tabular}{|c|c|c|c|c|c|}
\hline entry & $\mathrm{E}$ & product & yiel & & conditions \\
\hline 1 & 1 & $8 \mathrm{R}=\mathrm{CH}_{2} \mathrm{OH}$ & & & $\begin{array}{l}\text { Freshly cracked } \\
\text { anhydrous } \mathrm{CH}_{2} \mathrm{O}\end{array}$ \\
\hline 2 & 1 & $8 \mathrm{R}=\mathrm{CH}_{2} \mathrm{OH}$ & 0 & & $\begin{array}{l}35 \% \text { wt. aqueous } \\
\text { solution of } \mathrm{CH}_{2} \mathrm{O}\end{array}$ \\
\hline 3 & 2 & 9 & 41 & & '2' $\left(\mathrm{POCl}_{3}, \mathrm{DMF}\right)$ \\
\hline
\end{tabular}

${ }^{a}$ Isolated yields.

We found that the use of VH 2 resulted in the formation of unsaturated $\beta$-chloroaldehyde $\mathbf{9}$ as opposed to $\alpha$-functionalized ketones (Table 1, entry 3). 2 is prepared by simply mixing phosphorous(V) oxychloride $\left(\mathrm{POCl}_{3}\right)$ and $\mathrm{DMF}$ in a solvent. The products present multiple functional groups for further elaboration, and are complementary to the $\alpha$-functionalized ketones normally obtained in ACA/trapping protocols. We were unable to successfully trap this enolate with 3-9.

The conditions found to provide the best yield use 20 equiv. of 2 at $60{ }^{\circ} \mathrm{C}$. These conditions furnished the desired unsaturated $\beta$-chloroaldehydes in fair yields and require $\sim 20 \mathrm{~min}$ for complete consumption of the ACA enolate, after which the reaction should be carefully quenched at $0{ }^{\circ} \mathrm{C}$.

The trapping procedure shows tolerance (Scheme 2) to aromatic rings (examples $\mathbf{9}, \mathbf{1 0}, \mathbf{1 4}, \mathbf{1 6}$ ), an alkyl silane (example 11), an alkyl bromide (15) and a benzyl protected alcohol (example 16). When tert-butyldimethylsilyl protected alcohols were used (examples $\mathbf{1 3}$ and 14), free alcohols were obtained as the major product. For product $\mathbf{1 3 a}$, formate ester $\mathbf{1 3 b}$ is also obtained.
Scheme 2. ACA-chloroformylation of 3-substituted cyclic enones.

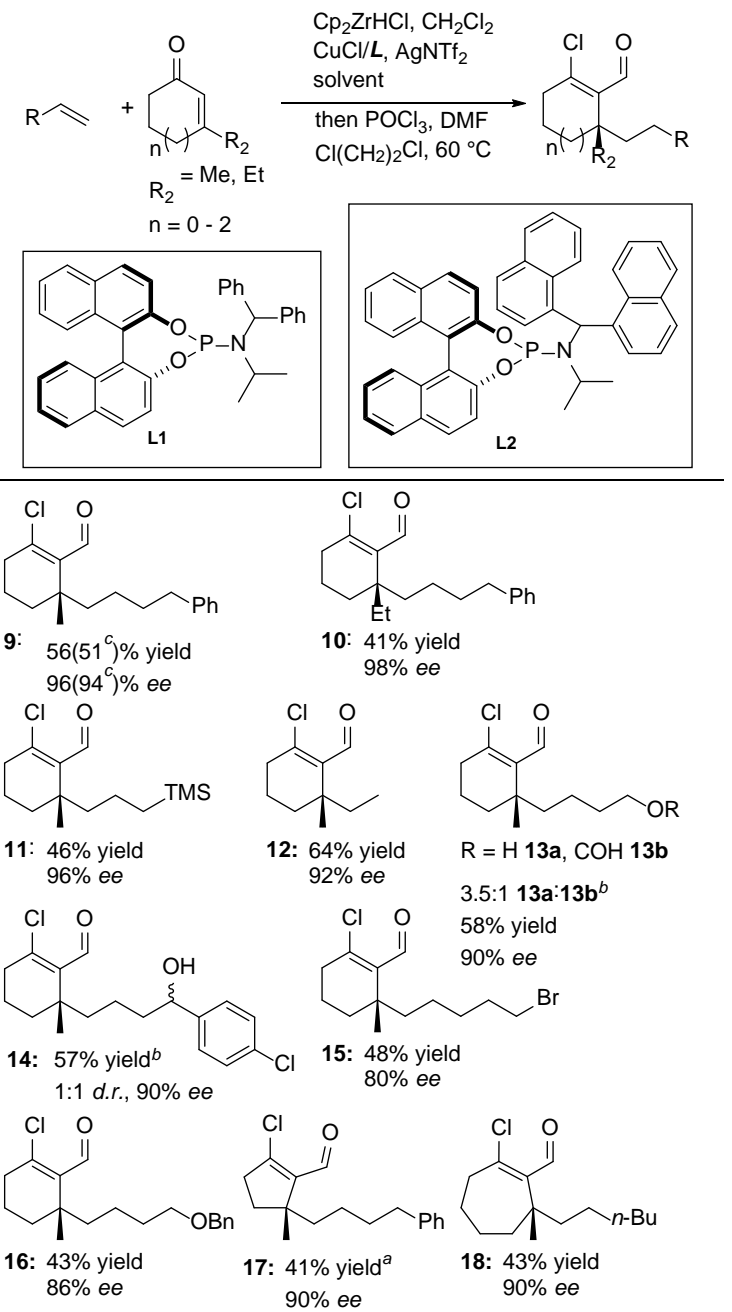

Isolated yields. Unless specified otherwise, ACA reactions were conducted using $\mathbf{L} 1$ with MTBE as solvent. $e e$ 's determined by HPLC or SFC. ${ }^{a}$ ACA reaction conducted using $\mathbf{L} 2, \mathrm{Et}_{2} \mathrm{O}$ as solvent and TMSCl (5.0 eq.). ${ }^{b}$ Asymmetric addition using TBDMS protected alcohols. ${ }^{c} 5 \mathrm{mmol}$ scale to give $0.79 \mathrm{~g}$ of $\mathbf{9}$.

We performed the reactions on a $5 \mathrm{mmol}$ scale to give 0.79 g of 9 in 51\% yield with $94 \%$ ee. In this reaction, less 2 (10 rather than 20 equiv.) can be used without adversely affecting the yield, however 2 hours were required for complete consumption of the enolate.

The trapping procedure is suitable for the quaternary centre containing enolates to form six-, seven- ${ }^{13 \mathrm{~d}}$ and fivemembered $^{13 \mathrm{~g}}$ ring containing products. The five-membered ring example $\mathbf{1 7}$ is of particular interest because 1,2,3trisubstituted cyclopentanes bearing a quaternary methyl stereocenter are common in natural products. ${ }^{2 \mathrm{a}, 18}$

Experiments to probe the trapping process were performed (Scheme 3). Treatment of hydroxymethylene cyclohexanone ${ }^{21}$ 19, a simple model for a 1,3-dicarbonyl which might be formed through formylation gave doubly chlorinated $\alpha, \beta, \delta, \gamma-$ unsaturated aldehyde $\mathbf{2 0}$ in 76\% isolated yield. No such dienes were observed in our reactions, suggesting against dicarbonyl (or tautomeric) intermediates (Scheme 3, A). Milder conditions ${ }^{19}$ as reported by a Genentech process group for the chlo- 
rination of cyclohexanone led to decreased yield (12\%, Scheme 3 B).

\section{Scheme $3 .^{c-d}$ Selected experiments for mechanistic studies}

A)

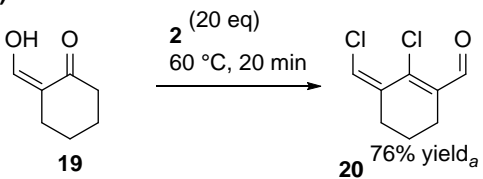

B)

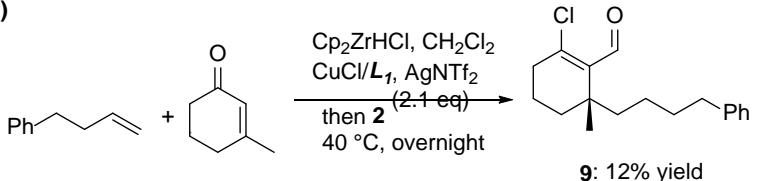

C)

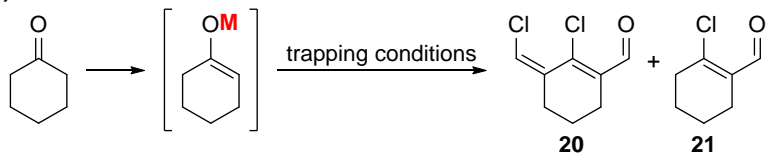

\begin{tabular}{llll}
\hline entry & $\mathbf{M}$ & trapping conditions & yield (19:20) \\
\hline $1^{f}$ & $\mathrm{Li}$ & $\mathbf{2}$ (20 eq.) $60^{\circ} \mathrm{C}, 1 \mathrm{hr}$ & $10(1: 0)$ \\
$2^{f}$ & $\mathrm{Cp}_{2} \mathrm{ZrCl}^{\mathrm{c}}$ & $\mathbf{2}$ (20 eq.) $60^{\circ} \mathrm{C}, 1 \mathrm{hr}$ & $48(1: 0)$ \\
$3^{f}$ & $\mathrm{H}^{e}$ & $\mathbf{2}$ (20 eq.) $60^{\circ} \mathrm{C}, 1 \mathrm{hr}$ & $4(1: 0)$ \\
$4^{a b}$ & $\mathrm{H}^{e}$ & $\mathbf{2}$ (2.1 eq.) $40^{\circ} \mathrm{C}, 27 \mathrm{~h}$ & $71(0: 1)$ \\
\hline
\end{tabular}

${ }^{a}$ Isolated yield. ${ }^{b}$ Data consistent with literature. ${ }^{17 a-c, 19}{ }^{c}$ Lithiation and transmetallation procedures carried out according to Evans and coworkers. ${ }^{20}{ }^{d}$ Unless specified otherwise, yields determined by ${ }^{1} \mathrm{H}$ NMR spectroscopy using $\mathrm{Cl}\left(\mathrm{CH}_{2}\right)_{2} \mathrm{Cl}$ as internal standard. ${ }^{e}$ Cyclohexanone was used. ${ }^{f}$ Yield based on average over two experiments.

Next, different enolates were investigated. Use of the lithium enolate ${ }^{20}$ gave only $10 \%$ yield of dichloride 20 and no mono-chloride 21 (Scheme 3, C, entry 1). Remarkably, the zirconium enolate $^{20}$ (formed via transmetallation of the lithium enolate with $\mathrm{Cp}_{2} \mathrm{ZrCl}_{2}$ ) gave $48 \%$ yield, exclusively of dichloride 20. Treating cyclohexanone (drawn as the enol) under optimized trapping conditions gave dichloride 20 in 4\% yield (Scheme 3, C, entry 3). Interestingly, Sandoval's conditions ${ }^{19}$ gave exclusively $\mathbf{2 1}$ in 71\% yield (Scheme 3, C, entry 4).

\section{Scheme 4. Possible mechanisms for chloroformylation}

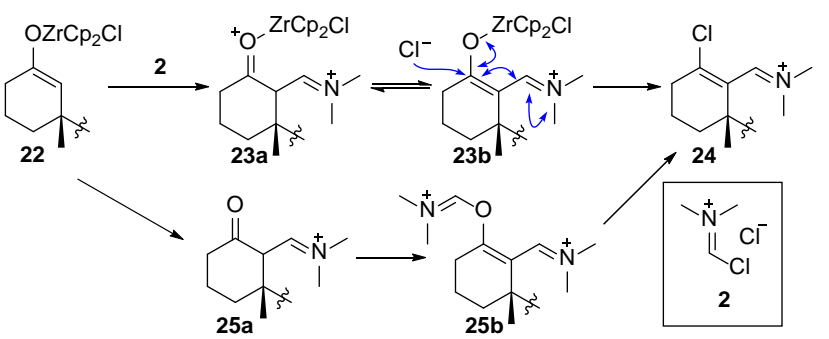

Plausible mechanisms for trapping are suggested in Scheme 4. The zirconium enolate $\mathbf{2 2}$ may react with $\mathbf{2}$ to form $\mathbf{2 3 a}$. Loss of hydrogen to $\mathbf{2 3 b}$, followed by chloride addition / elimination of an $\mathrm{O}-\mathrm{Zr}$ species would give iminium $\mathbf{2 4}$ and furnish the $\beta$-chloroaldehyde upon hydrolysis. Alternatively if $\mathbf{2 5 a}$ is formed from reaction with $\mathbf{2}$, another equivalent of $\mathbf{V H}$ could activate the oxygen via formation of $\mathbf{2 5} \mathbf{b}$. This species could then undergo substitution with $\mathrm{Cl}^{-}$as above to provide 24 .
The products obtained are well-suited for further functionalization (Scheme 5). The $\beta$-chloroaldehydes readily underwent Suzuki-Miyaura coupling with boronic acids to give products 26 and 27. Treatment of the products with Grignard reagents gave 1,2-addition products 28 (71\%) and 29 (67\%) both as a 1:1 mixture of diastereomers. Unsaturated $\beta$-chloroaldehyde $\mathbf{9}$ was also subject to condensation with 2-piperazinone in the presence of $N$-methylmorpholine to give dihydropyrrolopyrazinone 30. $^{19}$

Scheme 5. ${ }^{c}$ Examples of functionalized products and their starting materials

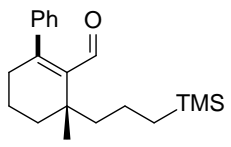

26: $56 \%$ yield $^{a}$ $92 \%$ ee

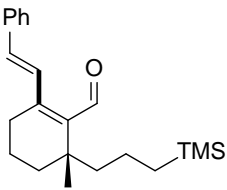

27: $73 \%$ yield $^{a}$
$92 \%$ ee<smiles>O/C=C/[Bi]</smiles><smiles>O</smiles><smiles>C=CCCCC1(C)CCCC(Cl)=C1[C@H](O)CCCS(C)(=O)=O</smiles>

28: $71 \%$ yield
$92 \%$ ee<smiles>C=CC[Mg]Br</smiles><smiles>CCC1(C)CCCC(Cl)=C1[C@H](O)c1cc(-c2ccccc2)ccc1C</smiles>

29 $67 \%$ yield $94 \%$ ee

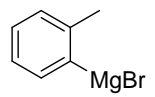<smiles>CC1(CCCCc2ccccc2)CCCc2c1cc1n2CCNC1=O</smiles><smiles>O=C1CNCCN1</smiles>

${ }^{a} 5.0 \mathrm{~mol} \% \mathrm{Pd}(\mathrm{OAc})_{2} / \mathrm{XPhos}, 3.0$ eq. $\mathrm{K}_{3} \mathrm{PO}_{4}, \mathrm{MeCN} / \mathrm{H}_{2} \mathrm{O} 5$ hrs. at $40{ }^{\circ} \mathrm{C}$. ${ }^{b}$ 2-oxopiperazinone/NMM ( $N$-methylmorpholine) in DMF. 5 hrs. at $115^{\circ} \mathrm{C}$. Isolated yields.

In summary, zirconium enolates from ACA reactions to form quarternary stereocenters were trapped using the Vilsmeier-Haack reagent in synthetically useful yields and high enantioselectivity. The method was shown to be scalable and is tolerant to functional groups. The products from the reaction were subjected to further derivatization and investigations are currently underway to apply this trapping procedure in complex molecule synthesis.

\section{ASSOCIATED CONTENT}

\section{Supporting Information}

The Supporting Information is available free of charge on the ACS Publications website. All procedures, characterization data, NMR spectra and chromatography traces (PDF)

\section{AUTHOR INFORMATION}

\section{Corresponding Author}

* stephen.fletcher@chem.ox.ac.uk

Notes

The authors declare no competing financial interests.

\section{ACKNOWLEDGMENT}


We thank the EPSRC EP/H003711/1 and the People Programme (Marie Curie Actions) of the European Union's Seventh Framework Programme (FP7/2007-2013) under REA grant agreement 316955 for funding.

\section{REFERENCES}

(1) a) Guo, H. C.; Ma, J. A. Angew. Chem. Int. Ed. 2006, 45, 354366. b) Chapman, C. J.; Frost, C. G. Synthesis 2007, 1-21. c) Jerphagnon, T.; Pizzuti, M. G.; Minnaard, A. J.; Feringa, B. L. Chem. Soc. Rev. 2009, 38, 1039-1075. d) Galestokova, Z.; Sebesta, R. Eur. J. Org. Chem. 2012, 6688-6695.

(2) For selected recent examples, see: a) Brown, M. K.; Hoveyda, A. H. J. Am. Chem. Soc. 2008, 130, 12904-12906. b) Mendoza, A.; Ishihara, Y.; Baran, P. S. Nat. Chem. 2012, 4, 21-25. c) Krasutsky, S. G.; Jacobo, S. H.; Tweedie, S. R.; Krishnamoorthy, R.; Filatov, A. S. Org. Process Res. Dev. 2015, 19, 284-289. d) Yu, X.; Su, F.; Liu, C.; Yuan, H.; Zhao, S.; Zhou, Z.; Quan, T.; Luo, T. J. Am. Chem. Soc. 2016, 138, 6261-6270. e) Cottet, P.; Bleschke, C.; Capdevila, M. G.; Tissot, M.; Alexakis, A. Adv. Synth. Catal. 2016, 358, 417-425. f) Zeng, M.; Murphy, S. K.; Herzon, S. B. J. Am. Chem. Soc. 2017, 139, 16377-16388.

(3) Murphy, S. K.; Zeng, M.; Herzon, S. B. Org. Lett. 2016, 18, 4880-4883.

(4) Murphy, S. K.; Zeng, M.; Herzon, S. B. Org. Lett. 2017, 19, 4980-4983.

(5) Drusan, M.; Rakovsky, E.; Marek, J.; Sebesta, R. Adv. Synth. Catal. 2015, 357, 1493-1498.

(6) Hung, Y. M.; Tseng, C. H.; Uang, B. J. Tetrahedron: Asymmetry 2015, 26, 1369-1374.

(7) Jarugumilli, G. K.; Zhu, C.; Cook, S. P. Eur. J. Org. Chem. 2012, 1712-1715.

(8) Germain, N.; Schlaefli, D.; Chellat, M.; Rosset, S.; Alexakis, A. Org. Lett. 2014, 16, 2006-2009.

(9) Bleschke, C.; Tissot, M.; Muller, D.; Alexakis, A. Org. Lett. 2013, 15, 2152-2155.

(10) Germain, N.; Guénée, L.; Mauduit, M.; Alexakis, A. Org. Lett. 2014, 16, 118-121.

(11) Germain, N.; Alexakis, A. Chem.-Eur. J. 2015, 21, 85978606.

(12) Gualandi, A.; Mengozzi, L.; Cozzi, P. G. Synthesis 2017, 49, 3433-3443.

(13) For relevant reviews, see: a) Maksymowicz, R. M.; Bissette, A. J.; Fletcher, S. P. Chem.-Eur. J. 2015, 21, 5668-5678. b) Pinheiro, D. L. J.; de Castro, P. P.; Amarante, G. W. Eur. J. Org. Chem. 2018, 4828-4844. For procedures used to form quaternary centers see: c) Maksymowicz, R. M.; Roth, P. M. C.; Fletcher, S. P. Nat. Chem. 2012, 4, 649-654. d) Sidera, M.; Roth, P. M. C.; Maksymowicz, R. M.; Fletcher, S. P. Angew. Chem. Int. Ed. 2013, 52, 7995-7999. e) Roth, P. M. C.; Sidera, M.; Maksymowicz, R. M.; Fletcher, S. P. Nat. Protoc. 2014, 9, 104-111 f) Gao, Z.; Fletcher, S. P. Chem. Sci. 2017, 8, 641-646. g) Ardkhean, R.; Mortimore, M.; Paton, R. S.; Fletcher, S. P. Chem. Sci. 2018, 9, 2628-2632.

(14) Maciver, E. E.; Maksymowicz, R. M.; Wilkinson, N.; Roth, P. M. C.; Fletcher, S. P. Org. Lett. 2014, 16, 3288-3291

(15) Nemethová, I.; Soradova, Z.; Sebesta, R. Synthesis 2017, 49, 2461-2469.

(16) Salmon, R. Oxalyl Chloride-Dimethylformamide. Encyclopedia of Reagents for Organic Synthesis; Wiley, 2001.

(17) a) Reddy, C. P.; Tanimoto, S. Synthesis 1987, 575-577. b) Mewshaw, R. E. Tetrahedron Lett. 1989, 30, 3753-3756. c) Kuchenbeiser, G.; Shaffer, A. R.; Zingales, N. C.; Beck, J. F.; Schmidt, J. A. R. J. Organomet. Chem. 2011, 696, 179-187. d) Usui, K.; Tanoue, K.; Yamamoto, K.; Shimizu, T.; Suemune, H. Org. Lett. 2014, 16, 4662-4665.

(18) For selected examples, see: a) Trost, B. M.; PissotSoldermann, C.; Chen, I. Chem.-Eur. J. 2005, 11, 951-959. b) Trost, B. M.; Dong, L.; Schroeder, G. M. J. Am. Chem. Soc. 2005, 127, 2844-2845. c) Hong, A. Y.; Krout, M. R.; Jensen, T.; Bennett, N. B.; Harned, A. M.; Stoltz, B. M. Angew. Chem. Int. Ed. 2011, 50, 27562760. d) Bennett, N. B.; Stoltz, B. M. Chem.-Eur. J. 2013, 19,
17745-17750. e) Dai, J.; Yoshida, W. Y.; Kelly, M.; Williams, P. J. Nat. Prod. 2016, 79, 1464-1467.

(19) Sandoval, C.; Lim, N.-K.; Zhang, H. Org. Lett. 2018, 20, 1252-1255.

(20) Evans, D. A.; McGee, L. R. Tetrahedron Lett. 1980, 21, 3975 $-3978$.

(21) Ainsworth, C. Org. Synth. 1959, 39, 27. 